\title{
SYNERGISTIC INFLUENCE OF PROPARGYL ALCOHOL AND ZINC SULFATE ON INHIBITION OF CORROSION OF ALUMINUM IN 0.5 $\mathrm{M} \mathrm{H}_{2} \mathrm{SO}_{4}$
}

\author{
FATEMEH BAGHAEI RAVARI ${ }^{a^{*}}$ ATHAREH DADGAREENEZHAD ${ }^{a}$
}

${ }^{a}$ Departement of Materials Science \& Engineering, Faculty of Engineering, Shahid Bahonar University, Kerman, Iran.

(Received: December 6, 2010 - Accepted: May 15, 2013)

\begin{abstract}
This paper describes the use of the Tafel polarization and electrochemical impedance spectroscopy technique (EIS) in order to study the corrosion inhibition process of aluminum in $0.5 \mathrm{M} \mathrm{H}_{2} \mathrm{SO}_{4}$ solution in presence of propargyl alcohol and zinc sulfate at the open circuit potential (OCP) in the room temperature. The Nyquist diagrams consisted of a capacitive semicircle at high frequencies followed by a well defined inductive loop at low frequency values. The impedance measurements were interpreted according to a suitable equivalent circuit. The results obtained showed that the addition of the propargyl alcohol inhibits the sulfuric acid corrosion of the aluminum. The inhibition efficiency increases with an increase in the propargyl alcohol concentration. The inhibition occurs through adsorption of the propargyl alcohol on the metal surface without modifying the mechanism of corrosion process. The inhibiting action propargyl alcohol is considerably enhanced by addition of zinc sulfate. Both the inhibitors obeyed the Langmuir isotherm and the thermodynamic calculations revealed that the adsorption of inhibitors was of physical nature.
\end{abstract}

Keywords: Electrochemical Techniques; Corrosion; Aluminum; Zinc Sulfate;

\section{INTRODUCTION}

Aluminum and its alloys find a wide spread spectrum of technological applications because of their particular properties such as low density, good appearance and corrosion resistance. For these reasons, the corrosion behavior of these materials has attracted the attention of several investigators. Acid solutions are used for pickling, chemical and electrochemical etching of aluminum and its alloys. It is very important to add a corrosion inhibitor to decrease the corrosion rate of aluminum and its alloys in such solutions. Several authors ${ }^{1-4}$ have studied the corrosion of aluminum and its alloys and their inhibition by organic inhibitors in acid solutions. The result of the investigations shows that acetylenic compounds are very effective in corrosion inhibition of metal in acid media [5]. Propargyl alcohol (PA) (2-propyn-1-ol) is one of the acetylenic alcohols and its inhibition effect has been discussed extensively ${ }^{5-10}$. The decisive role of the triple bonds of the PA molecule due to the $\pi$-electrons interacting with the metallic surfaces is generally accepted ${ }^{11-15}$. The adsorption of the inhibitor on the metal surface can markedly change the corrosion-resisting property of the metal $1^{6,7}$. The application of electrochemical impedance spectroscopy technique (EIS) as a new tool in corrosion research has resulted in a wealth of information concerning the methods of corrosion protection which were difficult to study with traditional dc techniques. This includes corrosion protection by conversion coatings ${ }^{8}$, polymer coating, and anodic films ${ }^{9}$. EIS has also provided information concerning corrosion protection by inhibitors ${ }^{10}$. In addition to specification of the physical properties of the system, the technique leads to important mechanistic and kinetic information ${ }^{16-18}$.

The present work aim is to investigate, by electrochemical methods, the synergistic behavior between PA and zinc ions in $0.5 \mathrm{M}$ sulfuric acid.

\section{EXPERIMENTAL}

The working electrodes employed in the present work were made of spec aluminum cylinder. This electrode was provided from the pure aluminum sample $(99.3 \%)$. The investigated material was cut as cylindrical rod, welded with $\mathrm{Cu}$-wire for electrical connection and mounted into epoxy resin of appropriate diameter using araldite to offer an active flat disc shaped surface of $\left(1 \mathrm{~cm}^{2}\right)$ geometric area for the aluminum sample, to contact the test solution. Prior to each experiment, the surface pretreatment of the working electrode was performed by mechanical polishing the electrode surface with successive grades of emery papers down to 2400 grit up to a mirror finish. The electrode was then, rinsed with acetone, distilled water, and finally dipped in the electrolytic cell. The experiments were performed in a $100 \mathrm{~cm}^{3}$ volume cell at room temperature, using Pt electrode as auxiliary and a Saturated Calomel Electrode (SCE) as reference electrode. All potentials given in this paper are referred to this reference electrode. The experiments were carried out in $0.5 \mathrm{M} \mathrm{H}_{2} \mathrm{SO}_{4}$ acid solutions devoid of and containing various concentrations of propagyl alcohol and zinc sulfate as inhibitors. All solutions were freshly prepared from analytical grade chemical reagents using doubly distilled water and were used without further purification. For each run, a freshly prepared solution as well as a cleaned set of electrodes was used. A Potentiostat/Galvanostat (EG\&G model 263A), and M352 corrosion software and frequency response analyzer (Princeton Applied Research Model 1020) were used for the polarization and EIS measurements, respectively.

The working electrode was stabilized in solution for $60 \mathrm{~min}$ prior to impedance run. EIS measurements were carried out using AC signals of amplitude $10 \mathrm{mV}$ peak to peak at the open circuit potential $\left(\mathrm{E}_{\mathrm{OCP}}\right)$ in the frequency range of $100 \mathrm{kHz}$ to $10 \mathrm{mHz}$. Tafel polarization curves were obtained using a sweep rate of $1 \mathrm{mV} / \mathrm{sec}$.

\section{RESULTS AND DISCUSSION}

\subsection{AC Impedance}

Fig. 1 shows the effect of various concentrations of $\mathrm{PA}$ on the impedance response of aluminum in $0.5 \mathrm{M} \mathrm{H}_{2} \mathrm{SO}_{4}$ solution at $\mathrm{E}_{\mathrm{OCP}}$. The data display that, each impedance diagram consists of a large capacitive loop at high frequencies (HF) and a small inductive one at low frequency values (LF) (Fig. 1a). The capacitive loop (at high frequencies) could be assigned to the relaxation process in the natural oxide presents on the surface of the aluminum sample and its dielectric properties ${ }^{17,19}$. Namely, the oxide film is considered to be a parallel circuit of a resistor due to the ionic conduction in the oxide film, and a capacitor due to its dielectric properties. The electrode impedance in this case was determined by the metal/oxide interface, the oxide film, and the oxide/ solution interface.

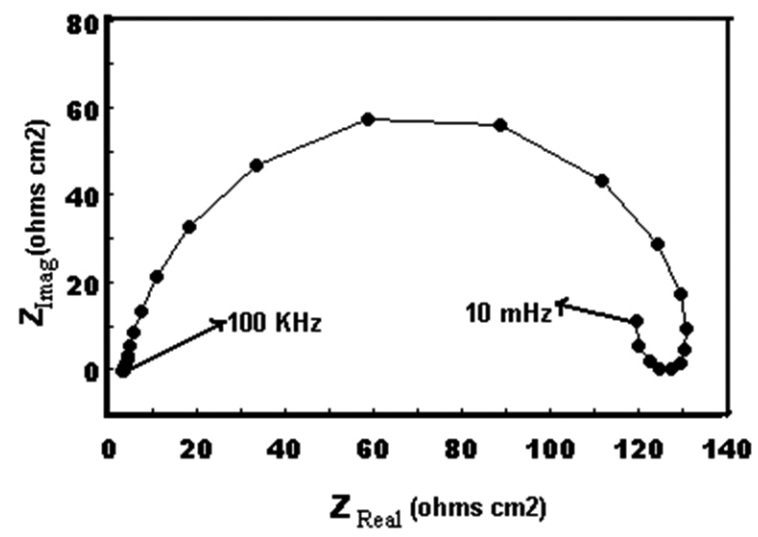

(a) 


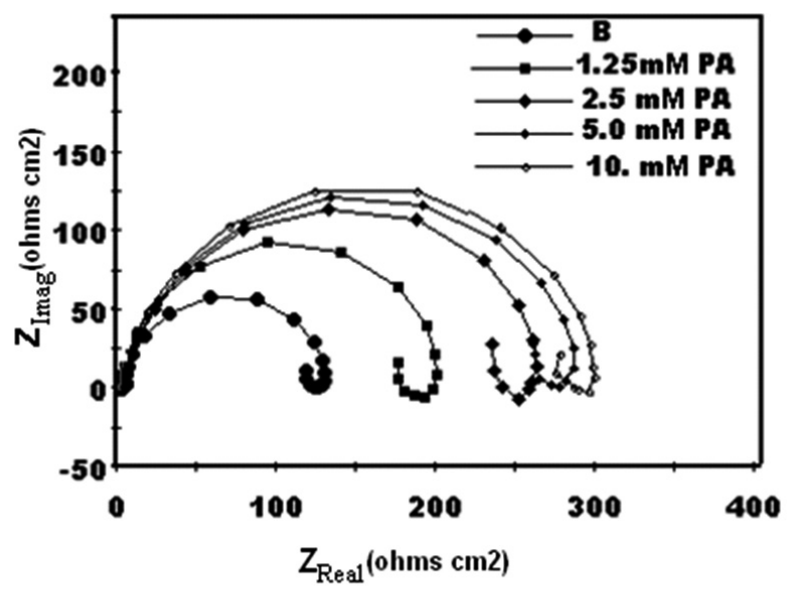

(b)

Fig 1. Nyquist plots of aluminum in $0.5 \mathrm{M} \mathrm{H}_{2} \mathrm{SO}_{4}$ (a) and with different concentration of PA(b).

The inductive loop (at low frequencies) could be attributed to the relaxation process in oxide nresents on the electrode surface al $H^{+}$obtained by adsorption species as $\left.\left(\mathrm{SO}_{4}^{2-}\right) \mathrm{SO}_{4}^{2-}\right)_{\text {ads }}$ and $\mathrm{H}_{a d g}^{+} \mathrm{H}_{\mathrm{adg}}^{+} \mathrm{H}_{\text {ads }}^{+}{ }^{19}$. These data are consistent with mechanism that proposed the adsorption of $\mathrm{SO}_{4}^{2-}$ ions on to the oxide surface forming oxide-sulfate aluminum in acidic solutions. The point of intersection between the inductive loop and the real axis represents $\left(R_{s}+R_{p}\right)$, where $R_{p}$ is the polarization resistance, which is defined as the dc limit of the impedance ${ }^{20}$.

It is essential to develop the appropriate models for the impedance which can be used to fit the experimental data and extract the parameters which characterize the corrosion process.

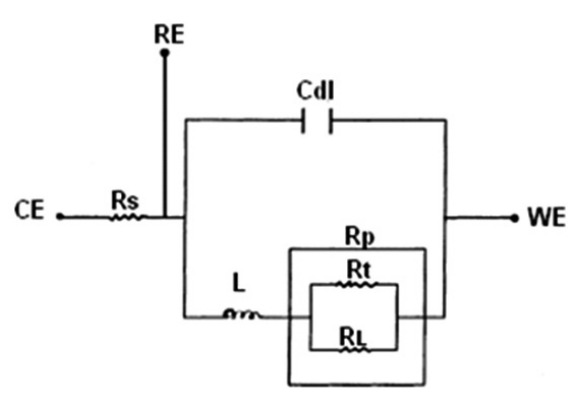

Fig. 2. The equivalent circuit model used to fit the experimental data

An equivalent circuit of five elements, depicted in Fig. 2, was used in simulation of the impedance data, as previously reported ${ }^{21}$. In this circuit, $\mathrm{C}_{\mathrm{dl}}$ is the double layer capacitance, $R_{t}$ is the interfacial charge-transfer resistance, $L$ is the inductance, and $R_{L}$ is the inductive resistance. When an inductive loop is present, the polarization resistance $R_{p}$ can be calculated from Eq.(1) ${ }^{22,23}$ :

$$
R_{P}=\frac{R_{t} \times R_{L}}{R_{t}+R_{L}}
$$

The measured complex plane impedance plot is similar to that calculated by the equivalent circuit model. The points in Fig. 1 and 2 represent the experimental data, while the solid curves represent the best fits.

The value of the polarization resistance $\left(\mathrm{R}_{\mathrm{p}}\right)$ is calculated from the difference of impedance at lower and higher frequencies ${ }^{7,8,20}$. To obtain the double layer capacitance $\left(\mathrm{C}_{\mathrm{dl}}\right)$, the frequency at which the imaginary component of the impedance is maximum (-Z"max), is found and $C_{\mathrm{dl}}$ values are obtained from the equation ${ }^{18}$.

$$
f\left(-Z_{\max }^{\prime \prime}\right)=\frac{1}{2 \pi c_{d l} R_{p}}
$$

The polarization resistance value was used to calculate the inhibition efficiency $(\eta(\%))$ of PA for aluminum at different concentrations, using equation:

$$
\eta(\%)=\frac{R_{p_{i}}-R_{P_{0}}}{R_{P_{i}}} \times 100
$$

Where $R_{p_{0}}$ and $R_{p_{0}}$ are the polarization resistances an inhibited and an uninhibited, respectively. Table 1 presents the numerical values of $\mathrm{R}_{\mathrm{p}}, \mathrm{C}_{\mathrm{d}}$ and inhibition efficiency $\eta(\%)$ for the aluminum sample in solution devoid of and containing various concentrations of the inhibitor.

Complete inspection of Table 1 reveals that in all cases, $R_{p}$ values increase, while those of $\mathrm{C}_{\mathrm{dl}}$ decrease with an increase in PA concentration. Thus, the corrosion rate decrease and inhibition efficiency increase with the increase of the PA concentration. It may be resulted from the fact that adsorption amount and the coverage of the PA on the electrode surface increases with increasing in the concentration.

Table 1. Electrochemical impedance parameters for aluminum in $0.5 \mathrm{M}$ $\mathrm{H}_{2} \mathrm{SO}_{4}$ with various concentrations of PA.

\begin{tabular}{|c|c|c|c|}
\hline $\mathrm{C}(\mathrm{mMol})$ & $\mathrm{R}_{\mathrm{p}}\left(\Omega \mathrm{cm}^{2}\right)$ & $\mathrm{C}_{\mathrm{dl}}\left(\mu \mathrm{Fcm}^{-2}\right)$ & $\eta(\%)$ \\
\hline Blank & 117 & 630 & -- \\
\hline 1.25 & 175 & 382 & 33.1 \\
\hline 2.5 & 236 & 177 & 50.4 \\
\hline 5 & 257 & 167 & 54.4 \\
\hline 10 & 275 & 162 & 57.5 \\
\hline
\end{tabular}

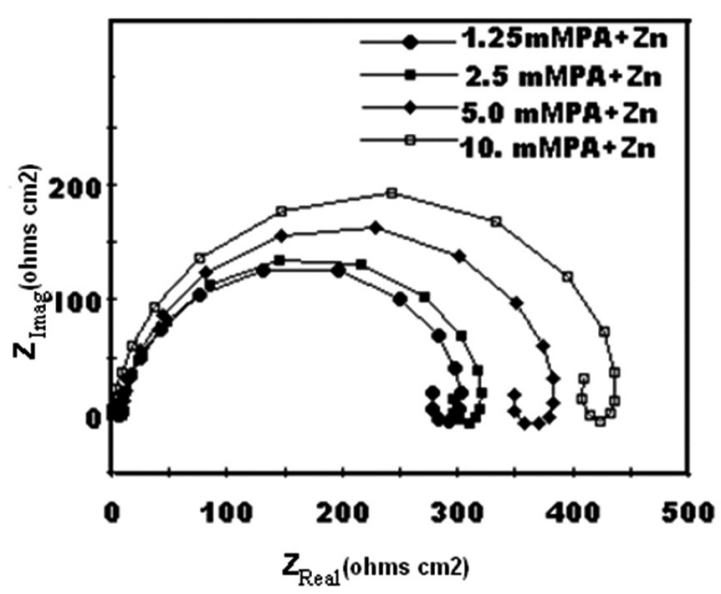

Fig. 3. The Nyquist plots of aluminum in $0.5 \mathrm{M} \mathrm{H}_{2} \mathrm{SO}_{4}$ solution with various concentrations of $\mathrm{PA}$ and in the presence of $0.01 \% \mathrm{zn}^{2+}$ ions.

Fig. 3 shows the Nyquist plots of the complex impedance of aluminum in $0.5 \mathrm{M} \mathrm{H}_{2} \mathrm{SO}_{4}$ solution with various concentrations of PA and in the presence of $0.01 \% \mathrm{Zn}^{2+}$. Table 2 indicates the impedance parameters derived from these curves.

It is found that the addition of $\mathrm{Zn}^{2+}$ ion does not change the general shape of the Nyquist plot but increases the polarization resistance and decreases the double layer capacitance. It is evident from Table 2 that inhibition efficiency values increase in the presence of $0.01 \% \mathrm{Zn}^{2+}$ ions. The inhibition efficiency values of PA in all concentrations increase markedly in the presence of $\mathrm{Zn}^{2+}$ ions. 
Table 2. Electrochemical impedance parameters for aluminum in $0.5 \mathrm{M}$ $\mathrm{H}_{2} \mathrm{SO}_{4}$ with various concentrations of PA and in the presence of $0.01 \% \mathrm{zn}^{2+}$ ions.

\begin{tabular}{|c|c|c|c|}
\hline $\begin{array}{c}\mathrm{C}(\mathrm{mMol}) \\
\mathrm{PA}+0.01 \% \mathrm{Zn}\end{array}$ & $\mathrm{R}_{\mathrm{p}}\left(\Omega \mathrm{cm}^{2}\right)$ & $\mathrm{C}_{\mathrm{dl}}\left(\mu \mathrm{Fcm}^{-2}\right)$ & $\eta(\%)$ \\
\hline Blank & 117 & 630 & -- \\
\hline 1.25 & 287 & 161 & 59.2 \\
\hline 2.5 & 302 & 149 & 61.3 \\
\hline 5 & 399 & 129 & 67.3 \\
\hline 10 & 409 & 113 & 71.5 \\
\hline
\end{tabular}

\subsection{Tafel (Potentiodynamic) polarization}

The Tafel polarization curves for aluminum in $0.5 \mathrm{M} \mathrm{H}_{2} \mathrm{SO}_{4}$ solution with various concentrations of PA are shown in Fig. 4. Corrosion current densities are obtained from Tafel curves by linear extrapolation of anodic and cathodic branches of Tafel slopes at point $50 \mathrm{mV}$ more positive and more negative than the corrosion potential values $\left(\mathrm{E}_{\text {corr }}\right)$.

The inhibition efficiency is defined as:

$$
\eta(\%)=\frac{l_{0}-t_{i}}{I_{0}} \times 100
$$

Where $\mathrm{I}_{0}$ and $\mathrm{I}_{\mathrm{i}}$ are corrosion current densities values without and with inhibitor, respectively. Values of corrosion current density $\left(\mathrm{I}_{\text {corr }}\right)$, corrosion potential $\left(\mathrm{E}_{\text {corr }}\right)$ and corrosion inhibition efficiency $\eta(\%)$ of aluminum for different concentration of $\mathrm{PA}$ in $0.5 \mathrm{M} \mathrm{H}_{2} \mathrm{SO}_{4}$ are given in Table 3 .

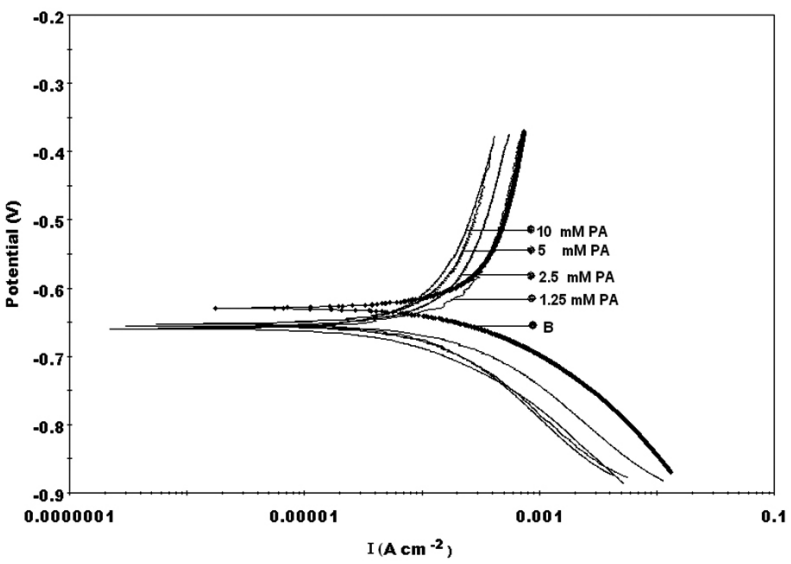

Fig. 4. Tafel polarization curves of aluminum in $0.5 \mathrm{M} \mathrm{H}_{2} \mathrm{SO}_{4}(\mathrm{~B})$ and with various of concentration PA

Table 3. Electrochemical polarization parameters for aluminum in $0.5 \mathrm{M}$ $\mathrm{H}_{2} \mathrm{SO}_{4}$ with various concentrations of PA

\begin{tabular}{|c|c|c|c|c|c|}
\hline $\begin{array}{c}\mathrm{C}(\mathrm{mMol}) \\
\mathrm{PA}\end{array}$ & $\begin{array}{c}\mathrm{E}_{\text {corr }} \\
(\mathrm{mV})\end{array}$ & $\begin{array}{c}\mathrm{b}_{\mathrm{c}}(\mathrm{mV} / \\
\mathrm{decad})\end{array}$ & $\begin{array}{c}\mathrm{b}_{\mathrm{a}}(\mathrm{mV} / \\
\mathrm{decad})\end{array}$ & $\begin{array}{c}\mathrm{I}_{\text {corr }}(\mu \mathrm{A} / \\
\left.\mathrm{cm}^{2}\right)\end{array}$ & $\eta(\%)$ \\
\hline Blank & -629 & 117 & 219 & 198 & -- \\
\hline 1.25 & -650 & 85 & 211 & 110 & 44.4 \\
\hline 2.5 & -654 & 115 & 167 & 88 & 55.5 \\
\hline 5 & -652 & 101 & 142 & 72 & 65.2 \\
\hline 10 & -659 & 96 & 123 & 58 & 70.7 \\
\hline
\end{tabular}

The data clearly show that, the addition of PA increases both of the anodic and cathodic over potentials, decreases the corrosion current density $\left(\mathrm{I}_{\text {corr }}\right)$. The open circuit corrosion potentials, $\mathrm{E}_{\text {cor }}$ are drifted to more negative values and markedly lowers both the anodic and cathodic Tafel slopes. These results indicate that this inhibitor acts predominately as mixed type.

The corrosion inhibition efficiencies of PA measured as a function of PA concentrations, using Tafel polarization and impedance methods are presented in Fig. 5. It is evident from this Table that the inhibition efficiencies of PA obtained from the polarization measurements are significantly higher than those obtained from the impedance measurements (Table 1).

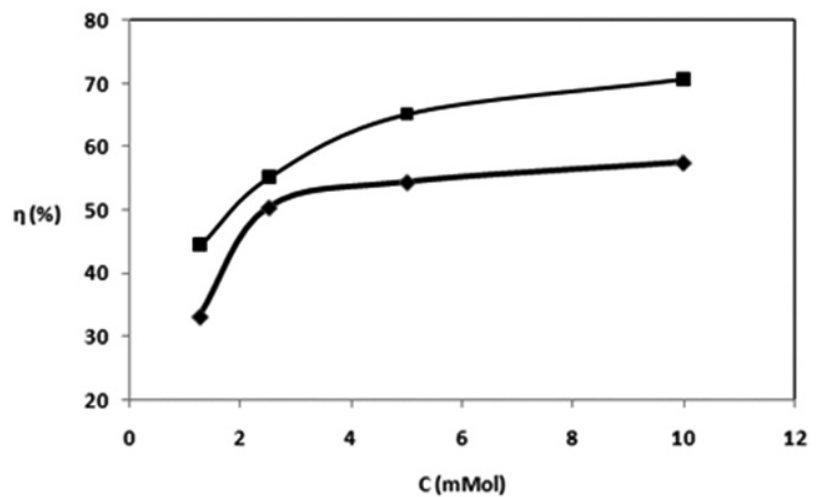

Fig. 5. Dependence of inhibition efficiency on the concentration of PA.Data obtained from the ( - ) polarization and ( $)$ impedance technique

The Tafel polarization curves for aluminum in $0.5 \mathrm{M} \mathrm{H}_{2} \mathrm{SO}_{4}$ solution with various concentrations of PA in the present of $0.01 \% \mathrm{Zn}^{2+}$ ions are shown in Fig. 6. The kinetic parameters obtained from these curves are presented in Table 4.

It is evident from Table 4 that inhibition efficiency values increase in the presence of $0.01 \% \mathrm{Zn}^{2+}$ ions. The inhibition efficiency values of PA in all concentrations increase markedly in the presence of $\mathrm{Zn}^{2+}$ ions and reached to a maximum value of $81.3 \%$. Both the anodic and cathodic Tafel slopes were altered significantly, but the reduction of the cathodic slopes was more significant than that of the anodic ones, especially at high concentrations.

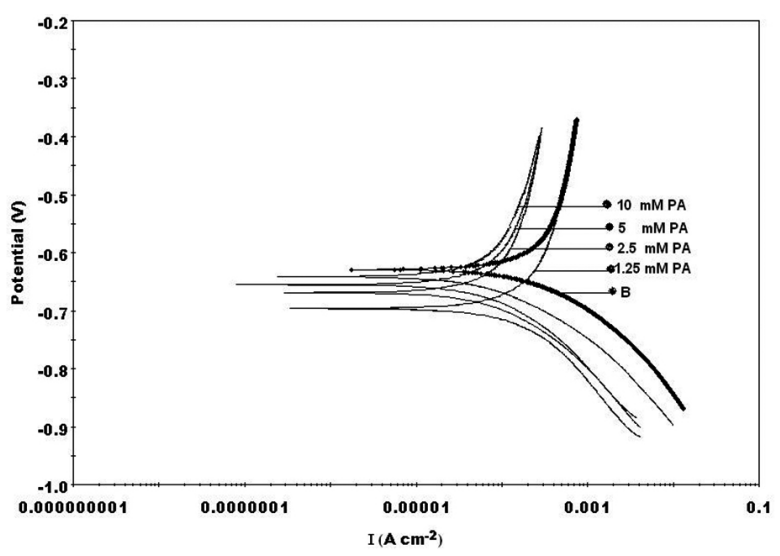

Fig. 6. Tafel polarization curves for aluminum in $0.5 \mathrm{M} \mathrm{H}_{2} \mathrm{SO}_{4}$ solution with various concentrations of PA in the present of $0.01 \% \mathrm{Zn}^{2+}$ ions.

Table 4. Electrochemical polarization parameters for aluminum in $0.5 \mathrm{M}$ $\mathrm{H}_{2} \mathrm{SO}_{4}$ with various concentrations of PA and in the presence of $0.01 \% \mathrm{zn}^{2+}$ ions.

\begin{tabular}{|c|c|c|c|c|c|}
\hline $\begin{array}{c}\mathrm{C}(\mathrm{mMol}) \\
\mathrm{PA}+0.01 \% \mathrm{Zn}^{2+}\end{array}$ & $\begin{array}{c}\mathrm{E}_{\text {corr }} \\
(\mathrm{mV})\end{array}$ & $\begin{array}{c}\mathrm{b}_{\mathrm{c}}(\mathrm{mV} / \\
\mathrm{decad})\end{array}$ & $\begin{array}{c}\mathrm{b}_{\mathrm{a}}(\mathrm{mV} / \\
\mathrm{decad})\end{array}$ & $\begin{array}{c}\mathrm{I}_{\text {corr }}(\mu \mathrm{A} / \\
\left.\mathrm{cm}^{2}\right)\end{array}$ & $\eta(\%)$ \\
\hline Blank & -629 & 117 & 219 & 198 & -- \\
\hline 1.25 & -696 & 95 & 143 & 68 & 65.5 \\
\hline 2.5 & -655 & 108 & 185 & 58 & 70.7 \\
\hline 5 & -669 & 90 & 118 & 46 & 73.7 \\
\hline 10 & -641 & 82 & 126 & 35 & 81.3 \\
\hline
\end{tabular}

Relatively good agreement was found between the inhibition efficiencies obtained from polarization and impedance techniques. Fig. 7 presents the corrosion inhibition efficiencies of $\mathrm{PA}+0.01 \% \mathrm{Zn}^{2+}$ calculated as a function 
of inhibitor concentrations, using polarization and impedance techniques. It is evident from this figure that the inhibition efficiencies of $\mathrm{PA}+0.01 \% \mathrm{Zn}^{2+}$ ions, obtained from the polarization measurements are significantly higher than those obtained from the impedance measurements.

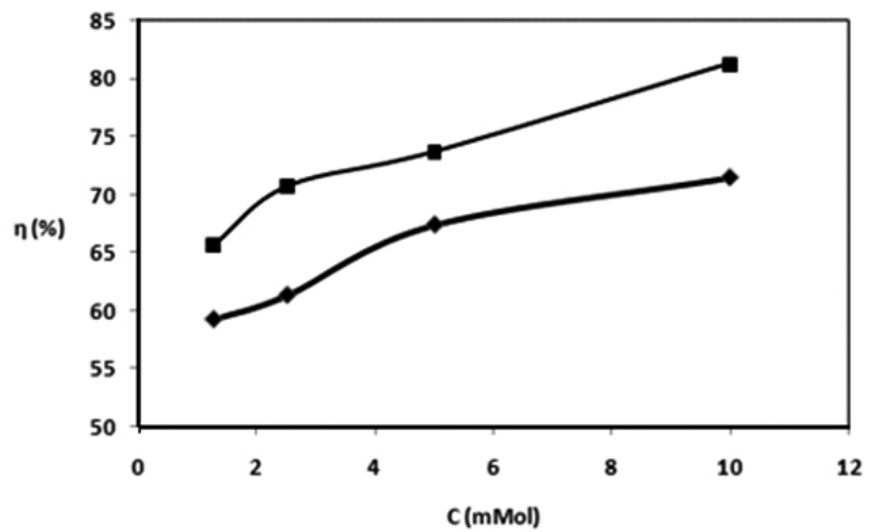

Fig. 7. Dependence of inhibition efficiency on the concentration of PA+ $\mathrm{Zn}^{2+}$ ions. Data obtained from the ($)$ polarization and ( $\left.\downarrow\right)$ impedance technique

\subsection{Synergistic effect of propargyl alcohol and $\mathrm{Zn}^{2+}$ ions}

For the evaluation of the synergistic effects between the two inhibitors, synergism parameter can be established as follows ${ }^{24}$ :

$$
S=\frac{1-E_{1,2}^{c a l c}}{1-E_{1,2}^{m e a s}}
$$

Where $E_{1,2}^{\text {calc }}$ is the calculated inhibition effect supposing additivity (no interaction between the inhibitor compound exits). can be expressed by:

$$
E_{1,2}^{\mathrm{calc}}=\mathrm{E}_{1}+\mathrm{E}_{2}-\mathrm{E}_{1} E_{2}
$$

Where $\mathrm{E}_{1}=1-\mathrm{I}_{1} \mathrm{I}_{0}, \mathrm{E}_{2}=1-\mathrm{I}_{2} / \mathrm{I}_{0}$ and $=1-\mathrm{I}_{12} / \mathrm{I}_{0}$, and $\mathrm{I}_{1}$ is corrosion current density for cation $\left(\mathrm{Zn}^{2+}\right)$; $\mathrm{I}_{1}$ the measured corrosion current density for PA $+0.01 \% \mathrm{Zn}^{2+}$ containing solution; $\mathrm{I}_{0}$ the corrosion current density for blank solution. The expression for $\mathrm{S}$ can be simplified to:

$$
S=\frac{L_{1} l_{2}}{l_{12} l_{0}}
$$

$\mathrm{S}$ approaches 1 when no interaction between the inhibitor compounds exists, while $\mathrm{S}>1$ points to a synergistic effect. In the case of $\mathrm{S}<1$, the antagonistic interaction prevails, which may be attributed to competitive adsorption.

Values of $S$ are given in Table 5. Most values are grater than unity. This result suggests that the improvement in inhibition efficiency generated by the addition of zinc sulfate to propargyl alcohol is due to a synergistic effect ${ }^{24}$.

It is seen that, the values of synergism parameter (S) attained a maximum value of 1.15 , at concentration of the optimum concentration of PA and $0.01 \%$ $\mathrm{Zn}^{2+}$ ions. PA.

Table 5. Value of synergism parameter (S) for different concentration of

\begin{tabular}{|c|c|}
\hline $\mathrm{C}(\mathrm{mMol}) \mathrm{PA}+0.01 \% \mathrm{Zn}^{2+}$ & $\mathrm{S}$ \\
\hline 1.25 & 1.12 \\
\hline 2.5 & 1.05 \\
\hline 5 & 1.09 \\
\hline 10 & 1.15 \\
\hline
\end{tabular}

\section{Adsorption isotherms and inhibition mechanism}

Adsorption isotherms are often shown to demonstrate the performance of organic adsorbent-type inhibitors. The simplest, being Langmuir isotherm, is based on the assumption that all adsorption sites are equivalent and that particle binding occurs independently from nearby sites being occupied or not. Langmuir isotherm can be expressed $\mathrm{as}^{25}$ :

$$
\frac{c}{\theta}=c+\frac{1}{K_{a d s}}
$$

Where $K_{a d s}$ is the adsorption equilibrium constant; $C$ is the inhibitor concentration and $\theta$ is the surface coverage. In this case $\theta$ is numerically identical to the value of the percentage inhibition efficiency, obtained from polarization or impedance techniques, divided by $100: . \theta=\eta / 100^{26}$. Regarding to the $\mathrm{Eq}(8)$, a linear relationship is observed when $\mathrm{C} / \theta$ is plotted as a function of $C$, with a slope of ideally unity. In the following, the polarization data, reported in Tables 3 (for PA) and Table 4 (for PA+ $0.01 \% \mathrm{Zn}^{2+}$ ), were used for calculations.

Fig. 8 shows the adsorption isotherm plot of $\mathrm{PA}$ on the surface of aluminum alloy in $0.5 \mathrm{M} \mathrm{H}_{2} \mathrm{SO}_{4}$ solution. The linear relationship of $\mathrm{C} / \theta$ versus $\mathrm{C}$ showed that inhibitor obeyed Langmuir adsorption isotherm. In this case, the line had a slope of 1.25 and the correlation coefficient $\left(\mathrm{R}^{2}\right)$ was 0.9973 . Fig. 9 shows the adsorption isotherm plot of PA+ $0.01 \% \mathrm{Zn}^{2+}$ on the surface of aluminum alloy in $0.5 \mathrm{M} \mathrm{H}_{2} \mathrm{SO}$ solution. The linear relationship of $C / \theta$ versus $C$ showed that inhibitor obeyed Langmuir adsorption isotherm. In this case, the line had a slope of 1.17 and the correlation coefficient $\left(\mathrm{R}^{2}\right)$ was 0.9983 .The deviation of the slope from unity is often interpreted as a sign that the adsorbing species occupy more or less a typical adsorption site at the metal/solution interface ${ }^{26}$.

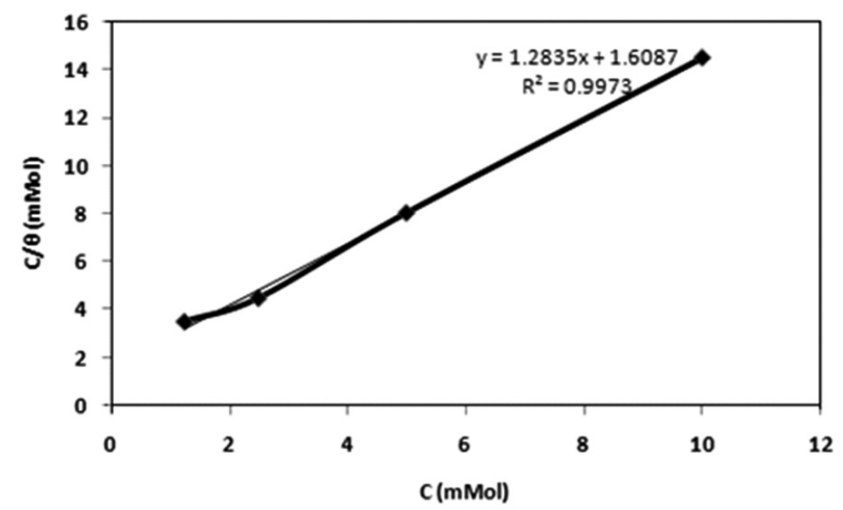

Fig. 8. Langmuir plot for $\mathrm{PA}$ on aluminum in $0.5 \mathrm{M} \mathrm{H}_{2} \mathrm{SO}_{4}$ solution

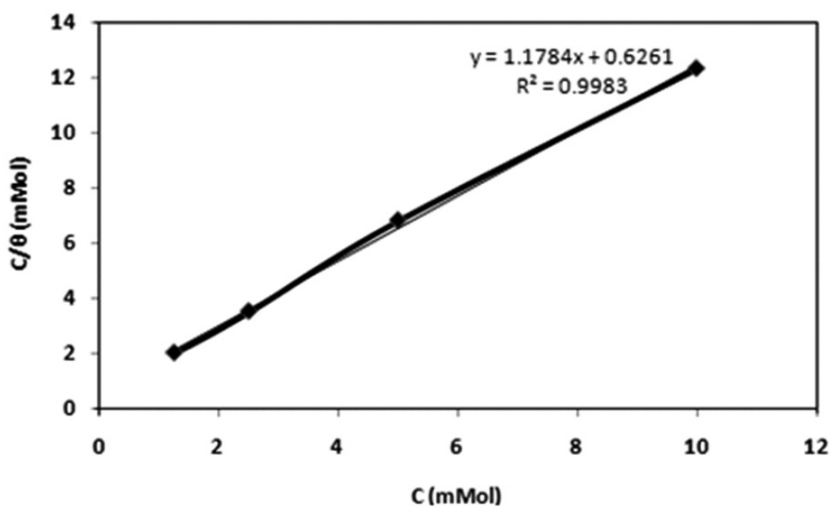

Fig. 9. Langmuir plot for $\mathrm{PA}+0.01 \% \mathrm{Zn}$ on aluminum in $0.5 \mathrm{M} \mathrm{H}_{2} \mathrm{SO}_{4}$ solution

The relationship between the adsorption constant and adsorption free energy is given by: 


$$
\Delta G_{a d s}^{0}=-R T L n K_{a d s}
$$

Where $\mathrm{R}$ is the universal gas constant and $T$ is the absolute temperature. The calculation of the adsorption equilibrium constant $K$ in this case yields a value of $621.6 \mathrm{dm} \mathrm{mol}^{3}$ which in turn leads to $\Delta G_{\text {ads }}^{0}=-15.95 \mathrm{~kJ} \mathrm{~mol}^{-1}$, for PA alone and the adsorption equilibrium constant $K$ for PA+ $0.01 \% \mathrm{Zn}^{2+}$, $1597.2 \mathrm{dm}^{3} \mathrm{~mol}^{-1}$, which in turn leads to and $\Delta G_{\text {ads }}^{\mathbf{0}}=-18.28 \mathrm{~kJ} \mathrm{~mol}$ ${ }^{l}$. The increasing value of $K_{\text {ads }}$ reflects the increasing adsorption capability, due to structural formation, on the metal surface ${ }^{27,28}$. The addition of $\mathrm{Zn}^{2+}$ ion increases the value of $K_{a d s}$. The negative value of $\Delta G_{a d s}^{0}$ indicate spontaneous adsorption of inhibitor molecule on the metal surface. The increasing value of $\Delta G^{0}{ }_{a d s}$ (toward the negative) reflects the increasing adsorption capability ${ }^{29}$.

The value found for PA on aluminum alloy thus clearly indicates that the adsorption is of the physical -nature, and that no covalent bond between inhibitor molecules and metal surface is established. Adsorption of the inhibitor explains this phenomenon, as solvent molecules (with high dielectric constant) within the electrical double layer become replaced with molecules with less pronounced dielectric properties. For this reason polar organic compounds can be adsorbed on the surface. In the neutral solution, propargyl alcohol is partially ionized and the ionized form of the alcohol can be strongly adsorbed on positively charged electrode surface. The addition of zinc sulfate did not change the adsorption behavior of PA. Langmuir adsorption was also observed for aluminum in the solutions in the presence of combined inhibitor $\left(\mathrm{PA}+\mathrm{Zn}^{2+}\right)$. The Nyquist plots of the electrode in solutions in the presence of PA is similar to that in the presence of $\left(\mathrm{PA}+\mathrm{Zn}^{2+}\right)$, as shown in Fig. 1 and Fig. 3. It can be concluded that the inhibition actions of $\left(\mathrm{PA}+\mathrm{Zn}^{2+}\right)$ are mainly attributed to the adsorption of PA. The zinc ions may compete with the PA inhibitor for the sites available for adsorption, but the adsorption of zinc ions stabilized the adsorption of PA on the metal surface so that the inhibition abilities of PA were improved by the combined use of PA and zinc ions. There was no evidence in the present work to demonstrate that the synergistic mechanism was due to electrostatic actions and physical interactions between PA and zinc ions.

\section{CONCLUSIONS}

The inhibition behavior of propargyl alcohol (PA) and its synergistic effect with zinc sulfate for aluminum in $0.5 \mathrm{M} \mathrm{H}_{2} \mathrm{SO}_{4}$ has been studied and the following conclusions can be drawn:

1. Propargyl Alcohol (PA) is an effective inhibitor in reducing the corrosion rate for aluminum in sulfuric acid solutions and its inhibition action is due to adsorption of PA molecules on the metal surface.

2. The inhibition efficiency of PA improves with increasing in PA concentration.

3. Synergistic effects between Propargyl Alcohol and zinc sulfate are observed. The addition of zinc sulfate in the solutions improves the inhibition efficiency of PA, significantly. In fact, the adsorption of Propargyl alcohol is stabilized by the presence of zinc sulfate in the solutions.

4- In this study the Langmuir adsorption isotherm provides a formal description of the adsorption behavior of the PA alone and $\mathrm{PA}+\mathrm{Zn}^{2+}$ on aluminum surface.

5-The values of the thermodynamic parameters for the inhibitor-metal interactions clearly indicate that the adsorption has physical nature for both PA and $\mathrm{PA}+\mathrm{Zn}^{2+}$ inhibitors.

\section{REFERENCES}

1- F. Ovari, L. Tomcsanyi, T. Turmezey, Electrochim. Acta .33, 323, (1988).

2- L. Tomcsanyi, K. Varga, I. Bartik, G. Horanyi, E. Maleczki, Electrochim. Acta. 34, 855,(1989) .

3- R.M. Stevanovic, A.R. Despic, D.M. Drazic, Electrochim. Acta. 33, 397, (1988).

4- A. Aytac, U. Ozmen, M. Kabasakologlu, Mater. Chem. Phys. 89, 176, (2005).

5- M.S. Morad, Mater. Chem. Phys. 60, 188, (1999).

6- N. Hackerman, J.D. Sudbury, J. Electrochem. Soc. 97, 109, (1950).

7- N. Hackerman, Corrosion, 18, 332t, (1962).

8- S.S. Abdel Rehim, H.H. Hassaan, M.A. Amin, J. Mater. Chem. Phys. 70, 64, (2001).

9- F.B. Growcock, V.R. Lopp, Corrosion , 4, 248, (1988).

10- F. Mansfeld, M.W. Kendig, J. Electrochem. Soc. 135, 828, (1988).

11- E.J. Duwell, J. Electrochem. Soc. 109, 1013, (1962).
12- I.L. Rozenfeld, Corrosion Inhibitors. McGraw-Hill, NY, 1981.

13- I.N. Putilova, A.M. Lolna, I.I. Suponitskaya, G.M. Maslova, Zashita Metall. 4, 392, (1968).

14- N.I. Podobaev, A.G. Voskresenskii, G.F. Semikoljonov, Zashchita Metallov, 3,112, (1967).

15- T. Kristof, T. Salamon, Werks. Korros. 41, 519, (1990).

16- F. Mansfeld, M.W. Kendig, W. Lorenz, J. Electrochem. Soc. 132, 290, (1985).

17- D.D. Macdonald, Electrochem. Acta. 35, 1501, (1990).

18- F. Mansfeld, S. Lin, S. Kim, H. Shin, Corros. Sci. 27, 997, (1987).

19- F. Mansfeld, S. Lin, S. Kim, H. Shih, Werkst. Korros. 39, 487, (1988).

20- W.J. Lorenz, F. Mansfeld, Corros. Sci. 21, 647, (1981).

21- J.R. Macdonald, Impedance Spectroscopy, John Wiley and Sons, NY, 1987.

22- I. Epelboin, C. Gabrielli, M. Keddam, in: E. Yeager, J.O.M. Bockris, B.E. Conway, S. Sarangapani (Eds.), Comprehensive Treatise of Electrochemistry, Wiley, 1985.

23- X. Cheng, G. Li, E.A. Kneer, B. Vermeire, H.G. Parks, S. Raghvan, J. Electrochem. Soc. 145, 352, (1998).

24- K. Armaki, N. Hackerman, J. Eletrochem. Soc. 115, 1007, (1968).

25- Z.S. Syed, S. Muralidharan, S. Venkatakrishna Lyer, B. Muralidharan, T. Vasudevan, Br Corros. J. 33, 297, (1998).

26- M. Hosseini, S.F.L. Mertens, M. Gorbani , Mater. Chem. Phys.78 , $800,(2003)$

27- P.W. Atkins, Physicals Chemistry, sixth ed. Oxford University Prees, 1999.

28- N. Hackerman, E.S. Jr. Snavely, Jr,J.S. Jr. Payne, J. Electrochem. Soc. 113, 677, (1966).

29- F.B. Growcock, V.R. Lopp, R.J. Jasinski, Corrosion. 135, 248, (1988). 